\title{
Immunotherapy: The New Strategy for Advanced Hepatocellular Carcinoma Treatment?
}

\author{
Antonia Digklia* \\ Department of Oncology, Centre hospitalier universitaire vaudois, Switzerland
}

Submission: February 07, 2017; Published: February 22, 2017

"Correspondence Address: Antonia Digklia, Department of Oncology, CHUV, 27, Rue Bugnon, Lausanne, CH-1011, Switzerland, Tel: 0041213140155; Email: antonia.digklia@chuv.ch

Abbreviations: HCC: Hepato-Cellular Carcinoma; AFP: Alpha-Feto-Protein; MAGE-A: Melanoma Antigen Gene A; NY-ESO-1: New YorkEsophageal Squamous cell Carcinoma-1; DCs: Dendritic Cells; CIK: Cytokine-Induced Killer; TUMAPs: Tumor-Associated Peptides; PD-L 1: Programmed Death-Ligand 1; TTP: Time to Tumor Progression

\section{Introduction}

Hepatocellular carcinoma (HCC) is one of the most common cancers worldwide. Despite its growing incidence, however therapeutic options remain limited and median survival in advanced setting has been short (less than 12months). The current standard of care is the multikinase inhibitor sorafenib [1]. The recently published phase III study RESORCE showed that regorafenib improves overall survival in patients with HCC who had disease progression during first-line treatment with sorafenib [2].

Although hepatocellular carcinoma is not generally considered an "immunogenic" tumor, rational for immunotherapy in patients with advanced HCC comes from a variety of observations. For example, Kojiro et al. [3] shows that patients with resected HCC with marked inflammatory cell infiltration (CD8+ and CD4+ T lymphocytes) have better prognosis [3]. Moreover, cancer testes antigens such as alphafetoprotein (AFP), melanoma antigen gene A (MAGE-A), and New York-esophageal squamous cell carcinoma-1 (NY-ESO-1) are expressed in HCC. Flecken et al. [4] showed that in patients with HCC who have spontaneous antigen-specific CD8+ T-cell responses have a better clinical outcome [4].

Despite the observations above, no significant progress had been made in this context until recently [5]. During the past ten years, several pilot trials tested the efficiency of cellular and non-cellular immunotherapy in this context. To date, only modest activity has been observed throughvaccination with mature autologous Dendritic Cells (DCs) alone or pulsed ex vivo with tumor cell lysate or AFP in patients with advanced disease [6,7]. In 2015, Lee et al. [8], presented interesting activity in the adjuvant setting with injections of activated cytokine-induced killer (CIK) cells [8]. In this study, 230 patients were randomised to be treated with activated autologous CIK cells after surgical resection, radiofrequency ablation or percutaneous ethanol injection versus no adjuvant therapy, leading to increased recurrence-free and overall survival (HR 0.63). Peptide based theurapeutic cancer vaccins are also being studied in this context, without relevant efficacy $[9,10]$. A European phase I/II trial studying the role of HepaVac, a vaccine comprising multiple newly identified tumor-associated peptides (TUMAPs) naturally presented on the surface of primary HCC cells is waiting to open in autumn 2017.

For the second year in arrow, immunotherapy hailed as the "clinical cancer advance of year 2016" by the American Society of Clinical Oncology based on notable progress in survival for patients with different advanced cancers previously considered intractable such as melanoma, lung and head and neck cancer based mainly on results of trials with checkpoint inhibitors. These are inhibitory monoclonal antibodies against cell surface proteins that down regulate T-cell activation. Inhibitory antibodies against Cytotoxic T lymphocyte-associated antigen 4 (CTLA-4) are the first to have reached clinical practice followed by monoclonal antibodies against Programmed death-ligand 1(PD-L1).

Tremelimumab is a monoclonal antibody against a cytotoxic T lymphocytes antigen named CTLA-4 (CTL antigen 4). In a small study including only 20 patients, $15 \mathrm{mg} / \mathrm{kg}$ of tremelimumab IV every 90 daysin patients with chronic hepatitis C showed $17.6 \%$ partial response rate in advanced HCC.Interestingly, although the patients received a suboptimal dose and there were also patients with Child Pugh B7 included, the treatment was well tolerated and there was a significant drop in the viral load [11]. 


\section{Cancer Therapy \& Oncology International Journal}

PD-1 expression by tumor infiltrated lymphocytes (TILs) and PDL-1 expression by tumor cells is not well established in HCC and do not have a predictive nor prognostic value for the time being. Nivolumab is a monoclonal antibody against PD-L1 which was tested in patients with advanced HCC ina phase I/II study. Update data was presented in the 2017 ASCO Gastrointestinal Cancers Symposium. The overall response rate (ORR) was $20 \%$ in 214 patients treated in the dose expansion phase with a 9-month overall survival rate of $74 \%$ (CheckMate- 040 cohort 2 ). Interestingly, responses were observed regardless of tumor PDL1 expression, sorafenib-naive and -treated patients and across different etiologies (HCV, HBV, alcohol etc).To date, adverse events were similar to profiles in other tumor types with most of the patients experiencing fatigue $(17 \%)$ and pruritus (12\%). Furthermore, Grade 3/4 ALAT and ASAT increase has been observed in about $6 \%$ each [12]. Clinical trials evaluating sorafenib vs nivolumab (NCT02576509) and nivolumab with or without ipilimumab vs sorafenib in first line setting are currently ongoing in advanced HCC (NCT01658878) as well as combination of other checkpoint inhibitors (NCT02966548), oncolytic virus (NCT02509507) and cancer vaccines.

Currently, combination of approaches of immunotherapy with other treatments, such asinterventional radiology procedure and stereotactic radiotherapyare also being explored. Recently, Duffy et al. [13], presented a pilot trial with 32 patients withrefractory HCC (Childs Pugh A/B7 and Barcelona Clinic Liver Cancer Stage B/C) treated with tremelimumab at two dose levels ( 3.5 and $10 \mathrm{mg} / \mathrm{kg}$ i.v.) every 4 weeks for 6 doses, followed by 3 monthsof infusions until progression or toxicity. On day 36 the patients underwent subtotal radiofrequency ablation or chemoablation. Median Time to Tumor Progression (TTP) was 7.4 months (95\% CI 4.7 to 19.4 months) with a median overall survival of 12.3 month [13].

\section{Conclusion}

These preliminary results are encouraging and fully support that immunotherapy regimens particularly immune checkpoint inhibitors will play an important role in HCC therapy in the near future. Furthermore, their toxicity profile is balanced by the manageable side effects as oncologists are aware of the specific guidelines that have been developed and broadly implemented during the past years. Ongoing clinical trials will help us not only to better clarify the optimal combination of immune therapies with other immunotherapy approaches, molecularly targeted agents and local ablative therapies in the treatment of HCC but also understand the optimal sequencing of these approaches.
Furthermore, we expect that translational research will help us to clarify the therapeutic role of targeted therapy and immunotherapy in order to select the most appropriate therapy for each patient.

\section{Reference}

1. Llovet JM, Ricci S, Mazzaferro V, Hilgard P, Gane E, et al. (2008) Sorafenib in advanced hepatocellular carcinoma. N Engl J Med 359(4): 378-390.

2. Bruix J, Qin S, Merle P, Granito A, Huang YH, et al. (2017) Regorafenib for patients with hepatocellular carcinoma who progressed on sorafenib treatment (RESORCE): a randomised, double-blind, placebocontrolled, phase 3 trial. Lancet 389(10064): 56-66.

3. Wada Y, Nakashima O, Kutami R, Yamamoto O, Kojiro M (1998) Clinicopathological study on hepatocellular carcinoma with lymphocytic infiltration. Hepatology 27(2): 407-414.

4. Flecken T, Schmidt N, Hild S, Gostick E, Drognitz O, et al. (2014) Immunodominance and functional alterations of tumor-associated antigen-specific CD8+ T-cell responses in hepatocellular carcinoma. Hepatology 59(4): 1415-1426.

5. Greten TF, Manns MP, Korangy F (2008) Immunotherapy of HCC. Rev Recent Clin Trials 3(1): 31-39.

6. Tada F, Abe M, Hirooka M, Ikeda Y, Hiasa Y, et al. (2012) Phase I/II study of immunotherapy using tumor antigen-pulsed dendritic cells in patients with hepatocellular carcinoma. Int J Oncol 41(5): 1601-1609.

7. Palmer DH, Midgley RS, Mirza N, Torr EE, Ahmed F, et al. (2009) A phase II study of adoptive immunotherapy using dendritic cells pulsed with tumor lysate in patients with hepatocellular carcinoma. Hepatology 49(1): 124-132.

8. Lee JH, Lee JH, Lim YS, Yeon JE, Song TJ, et al. (2015) Adjuvant immunotherapy with autologous cytokine-induced killer cells for hepatocellular carcinoma. Gastroenterology 148(7): 1383-1391.

9. Greten TF, Forner A, Korangy F, N Kontchou G, Barget N, et al. (2010) A phase II open label trial evaluating safety and efficacy of a telomerase peptide vaccination in patients with advanced hepatocellular carcinoma. BMC Cancer 10: 209.

10. Sawada Y, Yoshikawa T, Nobuoka D, Shirakawa H, Kuronuma T, et al. (2012) Phase I trial of a glypican-3-derived peptide vaccine for advanced hepatocellular carcinoma: immunologic evidence and potential for improving overall survival. Clin Cancer Res 18(13): 36863696.

11. Sangro B, Gomez-Martin C, de la Mata M, Iñarrairaegui M, Garralda E, et al. (2013) A clinical trial of CTLA-4 blockade with tremelimumab in patients with hepatocellular carcinoma and chronic hepatitis C. J Hepatol 59(1): 81-88.

12. Ignacio Melero BS, Thomas Cheung Yau, Chiun Hsu, Masatoshi Kudo, Todd S, et al. (2017) Nivolumab dose escalation and expansion in patients with advanced hepatocellular carcinoma (HCC): The CheckMate 040 study. J Clin Oncol 35 (suppl 4S; abstract 226).

13. Duffy AG, Ulahannan SV, Makorova-Rusher O, Rahma O, Wedemeyer H, et al. (2016) Tremelimumab in combination with ablation in patients with advanced hepatocellular carcinoma. J Hepatol 66(3): 545-551. 
This work is licensed under Creative Commons Attribution 4.0 License

DOI:_10.19080/CTOIJ.2017.03.555609

\section{Your next submission with Juniper Publishers} will reach you the below assets

- Quality Editorial service

- Swift Peer Review

- Reprints availability

- E-prints Service

- Manuscript Podcast for convenient understanding

- Global attainment for your research

- Manuscript accessibility in different formats

( Pdf, E-pub, Full Text, Audio)

- Unceasing customer service

Track the below URL for one-step submission https://juniperpublishers.com/online-submission.php 